
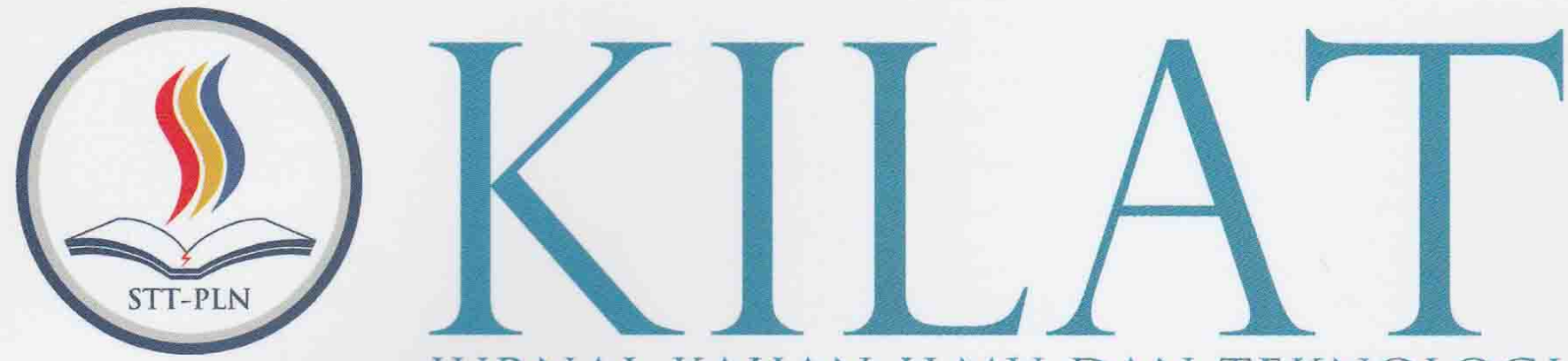

JURNAL KAJIAN ILMU DAN TEKNOLOGI

Endah Lestari: Irma Wirantina K: Ranti Hidayawanti

Faisal:

Muhammad Ridwan: Mardawati

Gita Puspa Artiani: Indah Handayasari

Kresna Ramanda; Irmawati Carolina

Ratna Mutu Manikam:

Farid Setiawan

Rayung Wulan

Roni Kartika Pramuyanti

Rr. Mekar Ageng Kinasti; Djoko Nugroho Notodisuryo

Satria;

Ayu Setiawati Agustini

Syam Gunawan: Pritasari Palupiningsih

Ali Ridho Gumelar: Anton: Ummu Radiyah

M. Yoga Distra Sudirman: Yessy Fitriani
ANALISA TAMAN ATAP DALAM UPAYA MENGURANGI LIMPASAN AIR HUJAN PADA BANGUNAN PERKOTAAN

OPTIMASI DIAGRAM LAYANAN PEMBELIAN DALAM MENDUKUNG MANAJEMEN HUBUNGAN PELANGGAN

OPTIMALISASI PENGOLAHAN SAMPAH ORGANIK DENGAN TEKNOLOGI BIODIGESTER SEBAGAI UPAYA KONSERVASI LINGKUNGAN

SELEKSI FITUR ALGORITMA NEURAL NETWORK MENGGUNAKAN PARTICLE SWARM OPTIMIZATION UNTUK MEMPREDIKSI KELAHIRAN PREMATUR

RANCANG BANGUN MEDIA BELAJAR FISIKA DASAR UNTUK MAHASISWA BERBASIS ANDROID

ANALISIS GLOBAL POSITIONING INFRASTRUKTUR DAN JARINGAN SOSIAL MEDIA DALAM BISNIS APLIKASI TRANSPORTASI DARAT ONLINE DI JAKARTA

PENGARUH INOVASI ANTENA PADA SIARAN TELEVISI MOBIL

PEMANFAATAN LIMBAH PEMBAKARAN BATUBARA (BOTTOM ASH) PADA PLTU SURALAYA SEBAGAI MEDIA TANAM DALAM UPAYA MENGURANGI PENCEMARAN LINGKUNGAN

PENERAPAN METODE GRAPHIC RATING SCALE (GRS) DALAM PENILAIAN KINERJA KARYAWAN

PEMBENTUKAN MODEL KLASIFIKASI DATA LAMA STUDI MAHASISWA STMIK INDONESIA MENGGUNAKAN DECISION TREE DENGAN ALGORITMA NBTREE

IMPLEMENTASI LOAD BALANCING DENGAN ALGORITMA EQUAL COST MULTI PATH (ECMP)

RANCANGAN SISTEM PENILAIAN HASIL KINERJA MULTI COMPANY DAN CROSS BUSINESS SECTOR 


\title{
ANALISIS GLOBAL POSITIONING INFRASTRUKTUR DAN JARINGAN SOSIAL MEDIA DALAM BISNIS APLIKASI TRANSPORTASI DARAT ONLINE DI JAKARTA
}

\author{
Rayung Wulan \\ Fakultas FTMIPA/Program Studi Informatika Universitas Indraprasta \\ utha2578@gmail.com
}

\begin{abstract}
ABSTRAK
Transportasi online, jenis transportasi yang akhir-akhir ini membuat orang-orang di dunia merasa dimudahkan dalam hal bertransportasi. Dengan cukup bermodalkan gadget dan aplikasi, kita bisa memesan transportasi yang nyaman dan lebih murah. Bahkan, transportasi online bersedia menjemput kita di rumah tanpa kita harus berpanas-panasan berjalan ke jalan raya dan menunggu angkutan. Benar-benar sangat dimanjakan dengan transportasi online ini. Namun, kesuksesan transportasi online di dunia ini, tak semerta-merta bebas dari permasalahan. Aplikasi bisnis transportasi online laju pertumbuhannya melesat cepat dengan fasilitas fasilitas yang cukup menjanjikan. Dengan model bisnis online menggunakan maps positioning konsumen dapat dengan mudah melihat dan menselaraskan terhadap kebutuhan mereka. Transaksi melalui Internet ini lebih dikenal dengan nama e-commerce dan e-business. Secara umum e-commerce diartikan sebagai segala bentuk transaksi perdagangan barang atau jasa (trade of goods and service) dengan menggunakan media elektronik/computer. Intinya jika tersedia sumber daya fisik atau proses bisnis yang saat ini dapat didigitalisasikan, maka disitulah kesempatan konsep e-business dapat diimplementasikan.
\end{abstract}

Keywords : Transportasi Darat Online, Global Positioning System, E-Commerce, Sosial media, Bisnis Aplikasi

\section{ABSTRACT}

Online transportation, the kind of transportation that lately makes people in the world feel eased in terms of transportation. With enough gadgets and applications, we can order a convenient and cheaper transportation. In fact, online transportation is willing to pick us up at home without us having to hitchhike down the highway and wait for the shuttles. Really very pampered with this online transport. However, the success of online transport in this world, not necessarily free of problems. The application of online transport business growth rate dashed quickly with facilities facilities are quite promising. With an online business model using consumer positioning maps can easily see and align to their needs. Transactions via the Internet is better known by the name of e-commerce and e-business. In general e-commerce is defined as any form of trade transactions of goods or services (trade of goods and services) by using electronic media / computer. Essentially, if there is a physical resource or business process that can currently be digitized, then that is where the e-business concept can be implemented.

Keywords: Online Land Transportation, Global Positioning System, E-Commerce, Social media, Business Applications

\section{PENDAHULUAN}

Dunia teknologi informasi perkembangannya semakin melaju pesat dalam beberapa tahun terakhir ini , pada tahun 2017 ini telah membawa dampak transformational pada berbagai aspek kehidupan, yang sangat fenomenal termasuk di dalamnya dunia bisnis transportasi online. Baru baru ini mulai ramai diperbincangkan dari segala aspek baik menurut per undang undangan, kepala dinas perhubungan darat bahkan menteri komunikasi dan informasi. Setelah berlalunya era "total quality" dan "reengineering", kini saatnya "era elektronik" yang ditandai dengan bisnis aplikasi online untuk berbagai kebutuhan .

Sangat dimanjakan dengan transportasi online ini, namun, kesuksesan transportasi online di dunia ini, tak semerta-merta bebas dari permasalahan. Permasalahan lain yang muncul adalah penerapan transportasi online yang jauh lebih murah ketimbang transportasi konvensional. Hal tersebut membuat pihak transportasi konvensional menduga bahwa transportasi online tidak membayar pajak ke Negara. Adanya demo tersebut juga diwujudkan dengan aksi mogok yang dilakukan oleh ribun taksi konvensional. Akibat dari aksi ini, banyak masyarakat awam yang menerima dampaknya, seperti sulitnya mendapatkan transportasi di jalan. Akhirnya banyak masyarakat yang terlantar tidak dapat pergi ke tempat tujuannya. Sampai saat ini, permasalahan ini belum mendapat solusi terbaik bagi kedua belah pihak, namun pihak transportasi online mengatakan akan menerapkan tarif dari pemerintah agar permasalahan ini tidak berbuntut panjang.

Salah satu konsep yang dinilai merupakan paradigma bisnis baru adalah e-business atau dikenal pula dengan bisnis aplikasi transportasi online sebagai isue isue yang relatif masih baru dan akan terus berkembang sesuai dengan lajunya pertumbuhan teknologi informasi. Bisnis aplikasi 
transportasi darat saat ini sangat menjanjikan bagi armada dan pengguna.

Dengan model bisnis online menggunakan maps positioning konsumen dapat dengan mudah melihat dan menselaraskan terhadap kebutuhan mereka.

Transaksi melalui Internet ini lebih dikenal dengan nama e-commerce dan e-business. Secara umum e-commerce diartikan sebagai segala bentuk transaksi perdagangan barang atau jasa (trade of goods and service) dengan menggunakan media elektronik/computer. Intinya jika tersedia sumber daya fisik atau proses bisnis yang saat ini dapat didigitalisasikan, maka disitulah kesempatan konsep e-business dapat diimplementasikan.

Perusahaan besar saat ini banyak menggunakan strategi dengan memanfaatkan informasi teknologi untuk berbagi sumber - sumber informasi dan meningkatkan efisiensi dan efektivitas dari proses bisnis dan mengembangkan strategi keterhubungan antara pelanggan, suplier, dan partner bisnis, yang dalam hal ini disebut Cross functional enterprise system ( $O^{\prime \prime}$ Brian \& Marakas, 2008). Bentuk arsitektur keterkaitan komponen dasar, proses, dan interface dari aplikasi e-business dan hubungannya satu sama lain, menggambarkan enterprise application architecture.

Enterprise Resource Planning (ERP) atau Perencanaan sumber daya Perusahaan adalah suatu sistem perusahaan yang bersifat lintas fungsional dan bertindak mengintegrasikan dan mengotomatiskan berbagai proses bisnis yang harus terpenuhi di dalam suatu perusahaan seperti kegiatan pabrikasi, logistik, distribusi, akuntansi, keuangan, dan fungsi sumber daya manusia. ERP juga merupakan sebuah software yang mengintegrasikan semua departemen.

\section{Global Positioning System (GPS)}

GPS atau Global Positioning System, merupakan sebuah alatatau sistem yang dapat digunakan untuk menginformasikanpenggunanya dimana dia berada (secara global) di permukaan bumi yang berbasiskan satelit. Data dikirim dari satelit berupa sinyal radio dengan data digital. Dimanapun anda berada, maka GPS bisamembantu menunjukan arah, selama anda melihat langit. Layanan GPS ini tersedia gratis, bahkan tidak perlu mengeluarkan biayaapapun kecuali membeli GPS recierver-rya. Sistem kerja GPS adalah dengan menstransmisikan sinyal dari satelit ke perangkat GPS (portable GPS murni, ataupun smartphone yang sudah memiliki fitur GPS).

GPS membutuhkan transmisi dari 3 satelit untuk mendapatkan informasi dua dimensi (lintang dan bujur), dan 4 satelit untuk tiga dimensi. Karena GPS bekerja mengandalkan satelit, maka penggunaannya disarankan di tempat terbuka. Penggunaan di dalam ruangan, atau di tempat yang menghalangi arah satelit (di angkasa), maka GPS tidak akan bekerja secara akurat dan maksimal. Setiap daerah di atas permukaan bumi ini minimal terjangkau oleh 3-4 satelit. Pada dasarnya, setiap GPS terbaru bisa menerima sampai dengan 12 chanel satelit sekaligus. Kondisi langit yang cerah dan bebas dari halangan membuat GPS dapat dengan mudah menangkap sinyal yang dikirimkan oleh satelit. Semakin banyak satelit yang diterima oleh GPS, maka akurasi yang diberikan juga akan semakin tinggi. Dengan system GPS inilah transportasi online dapat bekerja dengan baik, baik untuk pengguna atau pun pengemudi.

Sebuah GPS reciever harus mengunci sinyal minimal tigasatelit untuk memenghitung posisi 2D (latitude dan longitude) dan track pergerakan. Jika GPS reciever dapat menerima empat atau lebih satelit, maka dapat menghitung posisi 3D (latitude, longitude dan altitude). Jika sudah dapat menentukan posisi user, selanjutnyaGPS dapat menghitung informasi lain, seperti kecepatan, arah yang dituju, jalur, tujuan perjalanan, jarak tujuan, matahari terbit dan matahari terbenam dan masih banyak lagi.Satelit GPS dalam mengirim informasi waktu sangat presesi karena Satelit tersebut memakai jam atom.

Jam atom yang ada pada satelit jam dengan partikel atom yang di isolasi, sehingga dapat menghasilkan jam yang akurat dibandingkan dengan jam biasa.Perhitungan waktu yang akurat sangat menentukan akurasi perhitungan untuk menentukan informasi lokasi kita. Selain itu semakin banyak sinyal satelit yang dapat diterima maka akan semakin presesi data yang diterima karena ketiga satelit mengirim pseudo-random code dan waktu yang sama.

Cara kerja GPS secara logik menurut (Andi 2009)

1. Memakai perhitungan "triangulation" dari satelit.

2. Untuk perhitungan "triangulation", GPS mengukur jarak menggunakan travel time sinyal radio.

3. Untuk mengukur travel time, GPS memerlukan memerlukan akurasi

waktu yang tinggi.

4. Untuk perhitungan jarak, kita harus tahu dengan pasti posisi satelit dan ketingian pada orbitnya.

5. Terakhir harus menggoreksi delay sinyal waktu perjalanan di atmosfer sampai diterima receiver.

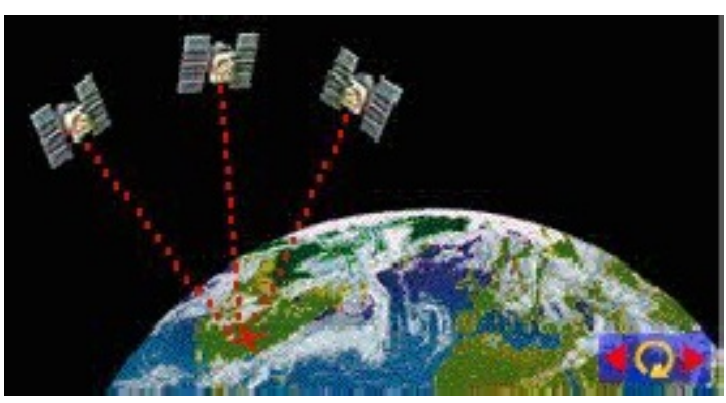

Gambar 1. Cara kerja satelit GPS mengirim sinyal (Sumber: Andi, 2009)

Satelit GPS berputar mengelilingi bumi selama 12 jam di dalam orbit yang akurat dia dan mengirimkan sinyal informasi ke bumi. GPS reciever mengambil informasi itu dan dengan menggunakan perhitungan "triangulation" menghitung lokasi user dengan tepat. 
Sistem Global Positioning System inilah yang menjadikan modal dasar penguna transportasi online di Jakarta.

\section{E-business dan E-Commerce}

Definisi e-business begitu banyak terdapat pada literature maupun internet, ini menandakan bahwa e-business semakin berkembang. Berikut ini adalah beberapa di antaranya:

1. E-business meliputi semua hal yang harus dilakukan menggunakan teknologi informasi dan komunikasi (ICT) untuk melakukan kegiatan bisnis antar organisasi maupun dari organisasi ke konsumen. (Sid L. Huff, dkk. 2000. Cases in Electronic Commerce. McGraw-Hill).

2. Menurut Kalakota dan Robinson (Kalakota, 2001) menuliskan bahwa e-business adalah sebuah paduan yang kompleks antara prosesproses bisnis, aplikasi-aplikasi perusahaan dan beberapa struktur organisasi yang dibutuhkan untuk menghasilkan suatu model bisnis yang memiliki performasnsi yang jauh lebih baik dari keadaaan sebelumnya.

3. E-business adalah praktek pelaksanaan dan pengelolaan proses bisnis utama seperti perancangan produk, pengelolaan pasokan bahan baku, manufaktur, penjualan, pemenuhan pesanan, dan penyediaan servis melalui penggunaan teknologi komunikasi, komputer, dandata yang telah terkomputerisasi. (Steven Alter. Information System: Foundation of E-Business. Prentice Hall. 2002).

4. Menurut Mohan Sawhney \& Jeff Zabin dalam O"Brien \& Marakas (2008) menyatakan bahwa e-business merupakan pemanfaatan jaringan elektronik dan teknologi-teknologi yang berkaitan untuk membolehkan, memperkuat, meningkatkan, merubah, atau menemukan suatu proses bisnis atau system bisnis yang mempunyai nilai yang lebih menguntungkan pelanggan saat ini ataupun pelanggan potensial.

5. Definisi lainnya menurut O"Brien \& Marakas dalam bukunya Management Information System (2008) menyatakan bahwa e-business adalah penggunaan teknologi internet untuk bekerja dan memberdayakan proses bisnis, ecommercedan kolaborasi dengan mitra bisnis seperti hubungan dengan pelanggan, pemasok, dan pemangku kepentingan bisnis lainnya.

Pada dasarnya e-business dapat dikatakan secara umum adalah pertukaran suatu nilai secara online. e-business dapat difenisikan adalah penggunaan teknologi informasi dan komunikasi oleh organisasi, individu, atau pihak-pihak terkait untuk menjalankan dan mengelola proses bisnis utama sehingga dapat memberikan keuntungan dapat berupa berupa keamanan, fleksibilitas, integrasi, optimasi, efisiensi, yang pada akhirnya dapat meningkatan produktivitas dan profit.

Perusahaan dapat mengandalkan aplikasi ebusiness untuk (1) reengineer proses bisnis internal, (2) implementasi system e-commerce terhadap konsumen dan supplier, (3) memajukan kolaborasi perusahaan antara tim bisnis dan kelompok kerja.

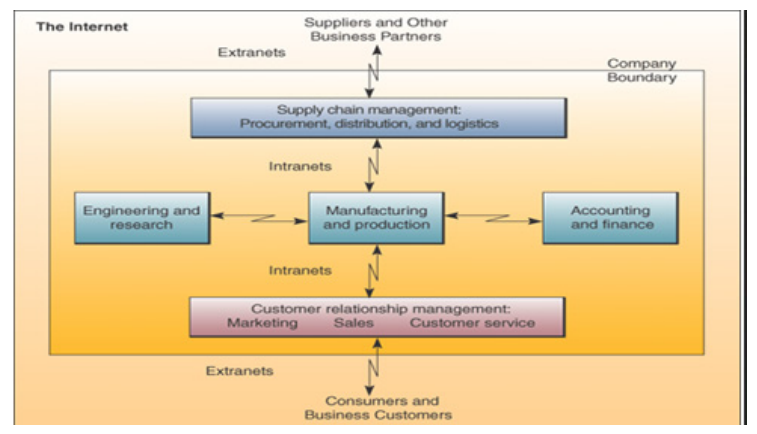

Gambar 2. Penggunaan aplikasi e-business saat ini Sumber : Nadiem Makarim (2010)

Perusahaan besar transportasi online saat ini banyak menggunakan strategi dengan memanfaatkan informasi teknologi untuk berbagi sumber - sumber informasi dan meningkatkan efisiensi dan efektivitas dari proses bisnis dan mengembangkan strategi keterhubungan antara pelanggan, suplier, dan partner bisnis, yang dalam hal ini disebut Cross functional enterprise system (O" Brian \& Marakas, 2008). Bentuk arsitektur keterkaitan komponen dasar, proses, dan interface dari aplikasi e-business dan hubungannya satu sama lain, menggambarkan enterprise application architecture seperti gambar dibawah ini.

Enterprise Resource Planning (ERP) atau Perencanaan sumber daya Perusahaan adalah suatu sistem perusahaan yang bersifat lintas fungsional dan bertindak mengintegrasikan dan mengotomatiskan berbagai proses bisnis yang harus terpenuhi di dalam suatu perusahaan seperti trasnportasi online yang mempunyai dan membutuhkan sumber daya manusia. ERP juga merupakan sebuah software yang mengintegrasikan semua departemen di jaringan sosial media.

\section{Jaringan Sosial Media}

Jaringan sosial media sebuah media online, dengan para penggunanya bisa dengan mudah berpartisipasi, berbagi, dan menciptakan isi meliputi blog, jejaring sosial, wiki, forum dan dunia virtual. Blog, jejaring sosial dan wiki merupakan bentuk media sosial yang paling umum digunakan oleh masyarakat di seluruh dunia. Situs jejaring sosial merupakan situs yang dapat membantu seseorang untuk membuat sebuah profil dan kemudian dapat menghubungkan dengan pengguna lainnya. Situs jejaring sosial adalah aplikasi yang memungkinkan pengguna untuk terhubung menggunakan profil pribadi atau akun pribadinya.

Menurut Burgon dan Huffner dalam Brent D Ruben dan Lea P Steward (2013 : 254) Media komunikasi adalah media perantara dalam peyampaian informasi dari komunikator ke komunikate yang bertujuan untuk efiseinsi penyampain informasi atau pesan. 
Dalam perjalanannya media komunikasi yang di urai secara terpisah kini sudah dapat dinikmati dalam satu gengaman, atau yang biasa di sebut one stop living. Media komunikasi yang berbasis internet dapat mewakili dari sekian banyak media komunikasi yang ada, media komunikasi yang bersifat klasik membuat semua menjadi tidak fleksibel sehingga terkesan dapat menghambat kegiatan manusia.

Menurut Blumer dan Katz ( $2009: 26$ ) bahwa penggunaan media berperan aktif untuk memilih dan menggunakan media tersebut. Jadi penggunaan media adalah pihak yang aktif dalam proses berkomunikasi. Pengguna media berusaha untuk mencari sumber media yang paling baik untuk memenuhi kebutuhannya.

Jaringan Sosial media juga mengacu pada suatu kategori Internet Aplikasi untuk membantu menghubungkan para teman, mitra bisnis, atau lain individu bersama-sama menggunakan berbagai perkakas. Aplikasi ini, mengenal sebagai jaringan sosial online sedang menjadi terus meningkat populer.

Jaringan Sosial media juga digunakan untuk menguji bagaimana perusahaan saling berhubungan satu sama lain, menandai orang banyak dengan koneksi informal yang menyambung para eksekutif, seperti halnya asosiasi dan koneksi antar karyawan individu pada perusahaan berbeda. Jaringan ini menyediakan jalan untuk perusahaan untuk mengumpulkan informasi, menghalangi kompetisi, dan bahkan collude didalam menentukan harga atau kebijakan.

\subsection{Latar Belakang Masalah}

1. Banyaknya sistem aplikasi bisnis online yang memanfaatkan sosial media sebagai bisnis online.

2. Tingkat kepercayaan masyarakat terhadap bisnis transportasi darat online sangat tinggi

3. Bisnis transportasi darat online berkembang sangat fenomenal melalui sosial media

\subsection{Tujuan Penelitian}

1. Membuat analisis perkembangan sosial media terhadap transportasi darat online

2. Melihat seberapa besar jaringan sosial media berpengaruh terhadap transportasi darat online.

\section{METODOLOGI PENELITIAN}

\subsection{Pendekatan Penelitian}

Metode penelitian yang penulis gunakan diantaranya metode kualitatif, adalah metode penelitian yang digunakan untuk meneliti pada kondisi obyek yang alamiah, di mana peneliti sebagai instrument kunci, teknik pengumpulan data dilakukan secara gabungan, analisis data yang bersifat induktif, dan hasil penelitian kualitatif lebih menekankan makna dari pada generalisasi.Menurut (Mukhtar 2013) Penelitian kuallitatif deskriftif adalah suatu metode yang digunakan untuk menemukan pengetahuan terhadap subyek penelitian pada suatu saat tertentu, kata deskriptif berasal dari bahasa latin 'deskriptivus' yang berarti uraian. Pendekatan yang dilakukan adalah melalui pendekatan kualitatif. Artinya data yang dikumpulkan bukan berupa angka-angka, melainkan data tersebut berasal dari naskah wawancara, catatan lapangan, dokumen pribadi, pengamatan, dan catatan resmi lainya berdasarkan sistem informasi yang didapat, sehingga yang menjadi tujuan dari penelitian kualitatif ini adalah ingin menggambarkan realita empirik dibalik fenomena secara mendalam, rinci dan tuntas. Oleh karena itu penggunaan pendekatan kualitatif dalam penelitian ini adalah dengan mencocokan antara realita empirik dengan teori yang berlaku dengan menggunakan metodologi kualitatif deskriftif. ( Lexy J moleong 2013 ).

\subsection{Pendekatan Penelitian}

Pendekatan dalam penelitian ini didasarkan pada pengalaman subjek terhadap fenomena itu yang terjadi dan apa pengalaman esensial orang lain terhadap fenomena itu. (Patton, 2012). Dengan strategi penelitian heuristik ini, si peneliti harus mempunyai pengalaman pribadi dan ketertarikan yang kuat terhadap fenomena yang sedang diteliti. Dalam strategi penelitian ini juga diposisikan jaringan sosial media yang turut memberi intensitas pengalaman terhadap suatu fenomena yang sedang diteliti. Baik peneliti dan media saling berbagi pengalaman dan pengetahuan terhadap suatu fenomena. Heuristik ini harus mempunyai pandangan yang mendalam. Dengan begitu, kita akan mendapatkan pandangan secara keseluruhan terhadap fenomena yang sedang diteliti terutama dalam penelitian mengenai analisa penerapan jaringan sosial media dalam trasnportasi darat online .

\subsection{Teknik Pengumpulan Data}

Teknik pengumpulan data yang digunakan diantaranya dengan mengumpulkan data primer dan sekunder. Data primer akan didapatkan melalui studi lapangan, interview (wawancara mendalam) dan observasi. Sedangkan data sekunder akan didapat dari buku-buku, jurnal-jurnal dan foto-foto/ gambar-gambar tentang analisis global positioning dan infrstruktur jaringan sosial media dalam bisnis transportasi online.

\subsection{Objek Penelitian}

Objek Penelitian ini diadakan pada 2 (dua) perusahaan Ojek Online terbesar di Indonesia yaitu PT Gojek Indonesia dan Grab Bike. Peneliti mengambil dua lokasi perusahaan Ojek Online ini karena banyaknya masyarakat terutama di Jakarta dan sekitarnya yang menggunakan transportasi Ojek Online dari perusahaan-perusahaan tersebut. Kedua objek penelitian ini dapat memberikan analisa yang representatif dan komprehensif terhadap analisa jaringan sosial media dalam bisnis transportasi darat online. 


\section{HASIL DAN ANALISA}

3.1 Inovasi dalam jaringan sosial media terhadap transportasi darat online

Jaringan sosial media dijadikan sarana yang sangat penting saat ini, dimana jaringan sosial media digunakan sebagai bisnis transportasi darat online.

Perubahan sistem jaringan sosial media terhadap bisnis transportasi darat online

Tabel Perbandingan transportasi online sebelum dan setelah

\begin{tabular}{|c|c|c|}
\hline No. & $\begin{array}{c}\text { Jaringan sosial media } \\
\text { sebelum ada } \\
\text { transportasi darat } \\
\text { online }\end{array}$ & $\begin{array}{c}\text { Jaringan sosial } \\
\text { media setelah } \\
\text { adanya trasnportasi } \\
\text { darat online }\end{array}$ \\
\hline 1. & $\begin{array}{l}\text { Hanya digunakan } \\
\text { secara terbatas }\end{array}$ & $\begin{array}{l}\text { Digunakan dalam } \\
\text { memesan transportsi } \\
\text { darat online }\end{array}$ \\
\hline 2. & $\begin{array}{l}\text { Tidak adanya standar } \\
\text { operasional pelayanan } \\
\text { dalam jaringan sosial } \\
\text { media }\end{array}$ & $\begin{array}{l}\text { Adanya peraturan } \\
\text { jaringan sosial media } \\
\text { yang harus } \\
\text { digunakan }\end{array}$ \\
\hline 3. & $\begin{array}{l}\text { Belum ada bisnis } \\
\text { transportasi darat } \\
\text { online yang } \\
\text { mengkolaborasikan } \\
\text { dengan analisis global } \\
\text { positioning }\end{array}$ & $\begin{array}{l}\text { Semakin banyak } \\
\text { bisnis dibidang } \\
\text { transportasi darat } \\
\text { online yang } \\
\text { menggunakan, } \\
\text { bahkan hampir } \\
\text { semua bisnis } \\
\text { transportasi darat } \\
\text { online }\end{array}$ \\
\hline 4. & $\begin{array}{l}\text { Digunakan hanya } \\
\text { sebatas mencari } \\
\text { kebutuhan }\end{array}$ & $\begin{array}{l}\text { Segala kebutuhan } \\
\text { ada didalam jaringan } \\
\text { sosial media, bisa } \\
\text { diantar yang kita } \\
\text { butuhkan saat ini. }\end{array}$ \\
\hline
\end{tabular}

\subsection{Perubahan cara pandang masyarakat} terhadap transportasi darat online

Cara pandang masyarakat tentang jaringan sosial yang biasanya sebagai media sosial hanya sebatas mencari hiburan kini telah berubah secara transformal Pertama adalah menggunakan jaringan sosial media, media televisi dan Interpersonal Communication Approach yang secara sengaja direncanakan dan direalisasikan perusahaan agar inovasi ini dapat diketahui oleh masyarakat luas. Jaringan sosial media sebagai media Penyampai transportasi darat online. Jaringan sosial media yang digunakan untuk media penyebar informasi tentang Gojek atau Grab baik lokasi, jenis kendaraan dsb.

Jaringan sosial media memanfaatkan banyak platform media sosial di antaranya Youtube, Facebook, Instagram dan berbagai komunitas virtual seperti Kaskus. Pada media sosial Youtube contohnya, banyak sekali iklan iklan yang ingin disampaikan Gojek tentang kisah hidup dari drivernya. Di dalam iklan yang dibuat Gojek tersebut ingin menampilkan bahwa jaringan sosial media telah ikut membantu bisnis transportsi darat online, dan membantu pemerintah akan peningkatan sosial ekonomi masyarakat. Selain itu juga, banyak infografik-infografik yang ditampilkan dari jaringan sosial media terhadap bisnis transportasi darat online.

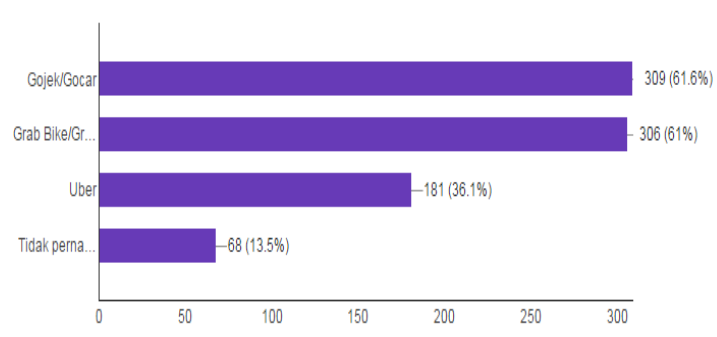

Gambar 3. Penggunaan aplikasi transportasi darat online saat ini

Sumber : Database kantor pusat grab (2015)

\section{KESIMPULAN DAN SARAN}

\subsection{Kesimpulan}

1. Menurut masyarakat, transportasi online saat ini sudah baik, terlihat dari bisnis transportasi darat online banyak yang menggunakan

2. Transportasi darat online menggunakan aplikasi jaringan sosial media disegala bidang

3. Adanya global positioning dan infrastruktur saat ini menjadikan berbagai bisnis menggunakan jaringan sosial media dalam bisnis yang ditekuni nya.

4. Perkembangan infrastruktur jaringan sosial media berkembang sangat fenomenal saat digunakan dalam bisnis transportasi darat online

4.2. Saran

1. Adanya kolaburasi antara jaringan infrastruktur dan sosial media menjadikan dunia transportasi darat online semakin melesat berkembangnya.

2. Diperbaiki sistem jaringan sosial media yang ada saat ini agar lebih tertata secara data basenya terpusat.

3. Menambah kenyamanan pengguna dalam bisnis transportasi darat online

4. Adanya penelitian lanjutan yang dapat mengembangkan penelitian transportasi darat online.

\section{DAFTAR PUSTAKA}

[1] Patton, Michaael Quinn. 2001. Qualitative Research and Evaluation Methods. Sage Publication : United States Of America

[2] Sugiono, Metode Penelitian Kuantitatif dan Kualitatif R\&D, Bandung, Alfabeta, 2012.

[3] Blumer dan Katz, Teknologi Komunikasi Mobile , Elex Media Komputindo, 2009

[4] Ruben D Brent dan Lea P Stewart, Komunikasi dan Prilaku Manusia , Jakarta, Raja Grafindo Persada, 2013.

[5] Andi off set, Apa dan bagaimana E-commerce , Yogyakarta, wahana komputer, 2012

[6] Moleong J lexy, Metode Penelitian Kualitatif, Edisi Revisi, Cetakan ke 13 Bandung, Remaja Rosdakarya, 2013. 
[7] Sugiono, Metode Penelitian Kuantitatif dan Kualitatif R\&D, Bandung, Alfabeta, 2012.

[8] Miles and Huberman, Teori dan Aplikasi Metode Penelitian, Cups publishing, 2004

[9] Basu , Strategi Periklanan pada e-Commerce Perusahaan Top Dunia, Andi, Yogyakarta, 2001

[10] Andi off set, Apa dan bagaimana E-commerce, Yogyakarta, wahana komputer, 2012.

[11] Blumer dan Katz, Teknologi Komunikasi Mobile, Elex Media Komputindo, 2009

[12] Turban,E.,\& King,D., E- Commerce , Elex Media Komputindo, 2002.

[13] Nofie, Internet Marketing for Beginners, Elex Media Komputindo, Jakarta, 2009

[14] Noegroho Agoeng, Teknologi Komunikasi, Yogyakarta, Graha IImu, 2010.

[15] Undang-undang nomor 11 tentang ITE Kementrian Komunikasi Dan Informasi Republik Indonesia tahun 2008. 